\title{
Synthesis of organofunctional silane from rapeseed oil and its application as a coating material
}

\author{
Karol Szubert $\mathbb{D}$
}

Received: 12 April 2018/Accepted: 27 August 2018/Published online: 1 September 2018

(C) The Author(s) 2018

\begin{abstract}
The possibility of using natural vegetable oils, such as rapeseed oil, for the synthesis of new organofunctional silanes has been shown. Vegetable oils are one of the most important groups of renewable products because of their accessibility and a wide range of applications. This research area concerns a possible application of the oils in chemical synthesis understood in a broad sense. A particular
\end{abstract}

subject of our interest was the application of organosilicon derivatives of rapeseed oil for producing protective wood coatings against water ingress. Due to the presence of alkoxysilyl groups and the use of sol-gel process, the coatings obtained were durably bonded to the wood surface.

Electronic supplementary material The online version of this article (https://doi.org/10.1007/s10570-018-2018-6) contains supplementary material, which is available to authorized users.

K. Szubert (西)

Faculty of Chemistry, Adam Mickiewicz University in

Poznan, Umultowska 89b, 61-614 Poznan, Poland

e-mail: karolszu@amu.edu.pl 


\section{Graphical abstract}
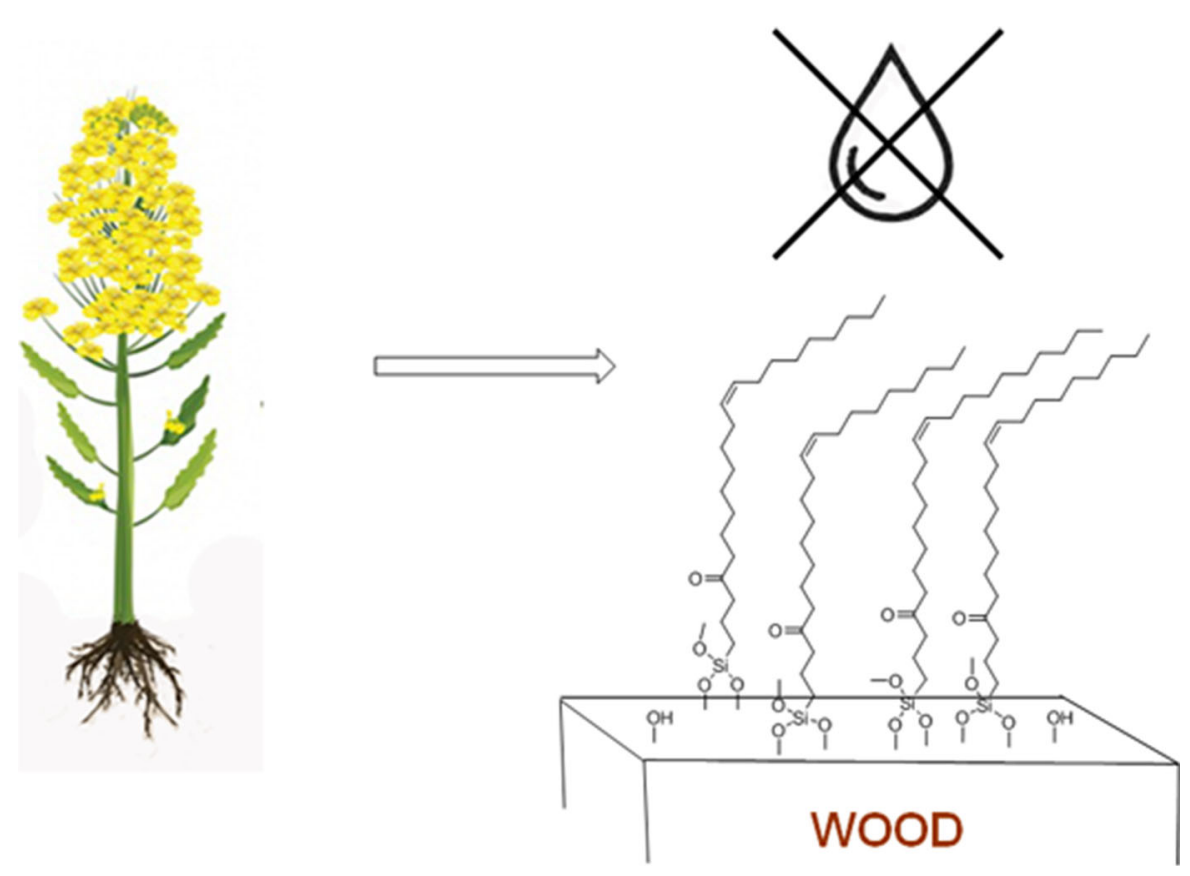

Keywords Renewable resources - Rapeseed oil · Sol-gel processes · Organically modified silanes . Wood protection

\section{Introduction}

Vegetable oils have been used for centuries not only for food, but also in many other applications, e.g. for the manufacture of paints, soap, and lubricants. Today, a wide range of oleochemicals are generated from them (Gunstone 2004; Gunstone and Hamilton 2001; Shahidi 2005; Spitz 2004). Vegetable oils are excellent substrates for different chemistries, hosting the reactive sites of ester groups, double bonds and allyl hydrogens (Biermann et al. 2000, 2011; Ronda et al. 2011; Xia and Larock 2010). The utilization of vegetable oils for industrial products is warranted from the standpoint of availability, stable prices, sustainability, ecological reasons (sequestration of carbon dioxide by plants), better properties and economics.

Rapeseed (Brassica napus L.) is the most important oilseed in Europe. Besides its use as a vegetable edible oil, rapeseed has also found industrial applications in the production of biodiesel and this is one of the reasons for the significant increase in its cultivation in recent years (Carré and Pouzet 2014). From the chemical point of view, long aliphatic chains present in vegetable oils can be used for the synthesis of, for example, new silanes and polysiloxanes with hydrophobic properties, that could be employed for the protection of different kind surfaces (wood, metal, concrete, etc.) against the effects of water.

Wood is one of the most important materials in the construction industry. Due to its organic constitution, wood is slowly destroyed by the long-term impact of water, oxygen and light under atmospheric conditions and this is why it requires a proper protection. Providing such a protection extends the life of wood products and hence their maintenance costs are significantly reduced (Goodell et al. 2003). There are several methods to protect wood, either by its chemical modification (Marney and Russell 2008; Naumann et al. 2012) or by its surface treatment (Subasri et al. 2013).

Unfortunately, many of the wood preservatives that have been used so far are highly toxic to humans and hence much attention has been paid to the development of nontoxic materials/methods for the protection of wood. Recently, several reports have been 
published on the use of inorganic-organic hybrid coatings for protection of wood substrates (Mai and Militz 2004b; Tshabalala and Gangstad 2003; Tshabalala and Sung 2007). The sol-gel process to produce hybrid coatings is quite versatile and even allows room-temperature deposition of hybrid inorganicorganic films on a wide range of substrates, including wood.

In this work, we would like to present the synthesis of new organofunctional silanes via nucleophilic substitution of 3-chloropropyltrimethoxysilane with sodium salts of fatty acids and their application to producing hydrophobic coatings on wood surfaces.

\section{Experimental}

\section{Materials}

The chemicals were obtained from Sigma-Aldrich and used without any additional preparatory steps. Rapeseed oil (ZT "Kruszwica" S.A., Poland) was purchased from a local grocery store. Pine wood boards, purchased from the lumber mill, were cut into smaller pieces of dimensions $70 \mathrm{~mm} \times 20 \mathrm{~mm} \times 10 \mathrm{~mm}$ (longitudinal $\times$ tangential $\times$ radial, respectively).

Synthesis of the rapeseed based silane

\section{Synthesis of rapeseed methyl esters (RME)}

Rapeseed oil (55 g) was added on vigorous stirring to a solution of $\mathrm{NaOH}(0.5 \mathrm{~g}, 0.0125 \mathrm{~mol})$ in methanol $(20 \mathrm{~mL})$ and stirred at room temperature for over $30 \mathrm{~min}$. After this time, the mixture was separated and the upper layer was washed thrice with brine $(0.2 \mathrm{~g}$ of $\mathrm{NaCl}$ in $10 \mathrm{ml}$ of water). The $R M E$ solution in methanol was dried with magnesium sulfate overnight and filtered. The pale-yellow $R M E$ solution in methanol was used for the synthesis of rapeseed sodium salt.

\section{Synthesis of rapeseed sodium salt}

$R M E$ solution in methanol (from the previous stage) was added upon vigorous stirring to a solution of $\mathrm{NaOH}(6.82 \mathrm{~g}, 0.17 \mathrm{~mol})$ in water $(30 \mathrm{~mL})$ and the stirring was continued for $30 \mathrm{~min}$ at $40{ }^{\circ} \mathrm{C}$. After this time, while vigorous stirring was continued, the mixture was added to brine $(200 \mathrm{~g} \mathrm{NaCl}$ in $500 \mathrm{ml}$ of water) and left to separate. The obtained solid rapeseed sodium salt was filtered, washed with methanol and dried under vacuum $(71.1 \mathrm{~g}, 90 \%$ yield calculated for rapeseed oil).

\section{Synthesis of the rapeseed based silane RPTMS}

The rapeseed sodium salt (40 g, 0,13 mol, calculated for sodium oleate) was added to $N, N$-dimethylformamide (DMF, $500 \mathrm{ml}$ ) followed by heating the obtained suspension to $80{ }^{\circ} \mathrm{C}$ and stirring until complete dissolution. Next KI $(1.3 \mathrm{~g}, 8 \mathrm{mmol})$ and 3-chloropropyltrimethoxysilane $(25 \mathrm{ml}, 0.137 \mathrm{~mol})$ were added and the reaction mixture was heated at $110{ }^{\circ} \mathrm{C}$ overnight. After this time, the mixture was subjected to filtration and DMF was evaporated under reduced pressure (51.8 g, yield: $89 \%$ ).

${ }^{1} \mathrm{H} \mathrm{NMR}\left(\mathrm{C}_{6} \mathrm{D}_{6}, 298 \mathrm{~K}, 500 \mathrm{MHz}\right) \delta=0.66(\mathrm{t}, 2 \mathrm{H}$, $\left.\mathrm{SiCH}_{2}-\right) ; 0.88$ (t, 3H, $\left.-\mathrm{CH}_{3}\right) ; 1.26-1.30$ (m, 20H, $\left.\mathrm{CH}_{2}-\right)$; 1.62 (m, 2H, Si- $\left.\mathrm{CH}_{2}-\mathrm{CH}_{2}-\right) ; 1.74$ (m, 2H, $\left.\mathrm{C}(\mathrm{O})-\mathrm{CH}_{2}-\mathrm{CH}_{2}-\right) ; 2.02\left(\mathrm{~m}, 4 \mathrm{H},-\mathrm{CH}_{2}-\mathrm{CH}=\right) ; 2.29$ (t, $\left.2 \mathrm{H}, \mathrm{C}(\mathrm{O})-\mathrm{CH}_{2}-\right) ; 3.58\left(\mathrm{~s}, 9 \mathrm{H}, \mathrm{Si}-\mathrm{O}-\mathrm{CH}_{3}\right) ; 4.04(\mathrm{t}, 2 \mathrm{H}$, $\left.-\mathrm{CH}_{2}-\mathrm{O}-\mathrm{C}(\mathrm{O})-\right) ; 5.36(\mathrm{~m}, 2 \mathrm{H},-\mathrm{CH}=\mathrm{CH}-)$ ppm.

${ }^{13} \mathrm{C} \quad \mathrm{NMR}\left(\mathrm{C}_{6} \mathrm{D}_{6}, 298 \mathrm{~K}, 126 \mathrm{MHz}\right) \delta=5.31$ $\left(\mathrm{SiCH}_{2}-\right) ; 14.05 \quad\left(-\mathrm{CH}_{3}\right) ; 22.66-31.89 \quad\left(-\mathrm{CH}_{2}-\right)$; $50.29\left(\mathrm{Si}-\mathrm{O}-\mathrm{CH}_{3}\right) ; 66.11\left(-\mathrm{CH}_{2}-\mathrm{O}-\mathrm{C}(\mathrm{O})-\right) ; 129.95$ $(-\mathrm{CH}=\mathrm{CH}-) ; 173.81(\mathrm{C}=\mathrm{O}) \mathrm{ppm}$.

$$
{ }^{29} \mathrm{Si} \quad \mathrm{NMR} \quad\left(\mathrm{C}_{6} \mathrm{D}_{6}, \quad 298 \mathrm{~K}, \quad 99 \mathrm{MHz}\right)
$$
$\delta=-42.47 \mathrm{ppm}$.

Modification of wood surface by the treatment with silane RPTMS

The wood samples were ultrasonically washed one after another with acetone, ethanol and deionized water for $5 \mathrm{~min}$ with each of the solvents. Then the cleaned samples were dried in an oven at $60{ }^{\circ} \mathrm{C}$ for $12 \mathrm{~h}$ and directly used for further modifications. Then a series of three $5 \%$ solutions of silane RPTMS in ethanol were prepared as specified in Table 1.

Acetic acid was added in the amount indispensable for adjusting $\mathrm{pH}$ of solutions to the value of about 4 . The measured $\mathrm{pH}$ values were 3.8 (for $\mathrm{O} 1$ ) and 3.9 (for $\mathrm{O} 2$ and $\mathrm{O} 3$ ). The solutions were stirred for $3 \mathrm{~h}$, except for the solution $\mathbf{O 3}$ that was stirred for $72 \mathrm{~h}$. After the stirring was completed, the samples of wood were fully submerged in the solutions for $1 \mathrm{~h}$. Then the samples were dried in air for $1 \mathrm{~h}\left(23{ }^{\circ} \mathrm{C}, 20 \%\right.$ 
Table 1 Amounts of reagents used for preparation of silane solutions

\begin{tabular}{llllll}
\hline Code & \multicolumn{2}{l}{ Reagents $[\mathrm{g}]$} & & \\
\cline { 2 - 6 } & RPTMS & Ethanol & $\begin{array}{l}\text { Acetic } \\
\text { acid }\end{array}$ & Water & TEOS \\
\hline O1 & 5 & 87 & 6 & 2 & - \\
$\mathbf{O 2}$ and $\mathbf{O 3}$ & 5 & 59 & 6 & 8 & 22 \\
\hline
\end{tabular}

TEOS tetraethoxysilane

humidity) followed by drying in an oven at $60{ }^{\circ} \mathrm{C}$ for $12 \mathrm{~h}$.

Analyses and measurements

${ }^{1} \mathrm{H}$ NMR (500 MHz), ${ }^{13} \mathrm{C}$ NMR (126 MHz), and ${ }^{29} \mathrm{Si}$ NMR (99 MHz) spectra were recorded on a Bruker Avance III $500 \mathrm{MHz}$ spectrometer at room temperature using chloroform-d $\left(\mathrm{CDCl}_{3}\right)$ as solvent.

The $\mathrm{pH}$ values of the solutions $\mathrm{O} 1-\mathrm{O} 3$ were measured using a pH meter FiveEasy F20 manufactured by Mettler-Toledo GmbH equipped with an electrode LE438. Before the measurements, the $\mathrm{pH}$ meter was calibrated with buffer solutions of $\mathrm{pH} 4.01$, 7.00 and 9.21 .

Scanning electron microscopy (SEM) images were taken on a FEI Quanta 250 FEG microscope equipped with an EDAX Energy Dispersive Spectroscopy detector (EDS). The images were taken in high vacuum mode with $10 \mathrm{kV}$ accelerating voltage. EDS mapping was realized with electron beam energy of $20 \mathrm{keV}$ using EDS Octane SDD detector (EDAX). The wood samples were prepared for SEM imaging by gluing onto the standard SEM carbon adhesive tape.

Fourier transform infrared (FT-IR) spectra were recorded on a Bruker Tensor 27 Fourier transform spectrometer equipped with a SPECAC Golden Gate diamond ATR (Attenuated total reflection) unit. In each case 16 scans were collected for a spectrum at the resolution of $2 \mathrm{~cm}^{-1}$. Measurements were carried out at three sites for each sample and the spectra were averaged using the OPUS Data Collection Program. While interpreting the spectra, characteristic bands were ascribed according to the literature (Stuart 2004).

Static water contact angle (WCA) measurements on all samples were made using a Krüss GmbH DSA 100 Expert Drop Shape Analyzer equipped with a software-controlled (DAS4 2.0): x, y, z-axis table, quadruple dosing unit with zoom and focus adjustment, illumination, and a camera with780 × $580 \mathrm{px}$ resolution. All presented data are arithmetic means from measurements made for 5 drops per sample. The measurements of contact angles were performed immediately after the deposition of a drop on a studied surface and the measurement time was about $1 \mathrm{~s}$.

Water absorption was measured for wood samples dried at $110{ }^{\circ} \mathrm{C}$ to constant mass, weighed to the accuracy of $0.001 \mathrm{~g}$, fully submerged in distilled water for $24 \mathrm{~h}$. Then the samples were taken out, dried with filter paper and weighed again. Percentage of absorbed water was calculated using the following equation:

$\% M=\frac{M_{\text {wet }}-M_{\text {cond }}}{M_{\text {cond }}} \times 100 \%$

where $\% \mathrm{M}$ is the percentage of absorbed water (\%); $\mathrm{M}_{\text {wet }}$ is the wet mass after submersion in water for $24 \mathrm{~h}$ ( $\mathrm{g}$ ); $\mathrm{M}_{\text {cond }}$ is the conditioned mass (initial dry mass) (g). All the obtained coatings were tested on three samples in parallel and the results were averaged.

\section{Results and discussion}

Synthesis of higher fatty acids derivatives

The synthesis of RPTMS was performed using commercially available edible rapeseed oil pressed from seeds of the double-low varieties (with very low glucosinolate content in seed meal and with no erucic acid in the seed oil). The oil contained, on the average, $60-65 \%$ of oleic acid (monounsaturated fatty acid, $\mathrm{C} 18: 1)$ and $7 \%$ of saturated fatty acids-palmitic (C16:0) and stearic (C18:0) acids as well as polyunsaturated fatty acids-linoleic (C18:2, 20\%), linolenic (C18:3, 10\%) and eicosenoic acids (C20:1, 1\%) (Bocianowski et al. 2012). Because of the problems with removal of glycerin, formed during vegetable oil saponification, this process was preceded by the reaction of oil transesterification leading to methyl esters of fatty acids (RME-rapeseed methyl esters) and the purified methyl esters were subjected to saponification in order to obtain a mixture of sodium salts of fatty acids. Then, as a result of nucleophilic substitution of 3-chloropropyltrimethoxysilane with sodium salts of fatty acids, in the presence of 
potassium iodide as a catalyst, the target organosilicon derivatives were obtained, according to the scheme 1 .

The synthesis of similar silanes in the reaction of 3-chloropropyltrimethoxysilane with sodium salts of carboxylic acids, such as disodium fumarate and sodium undecylate, in the presence of iminium phase transfer catalysts and with toluene as a solvent, has been disclosed (Backer et al. 2016). Unfortunately, in the conditions described in the relevant patent it is impossible to obtain vegetable oil derivatives because of the problem with dissolving their sodium salts in toluene. After $48 \mathrm{~h}$ of the reaction in toluene, the sodium salts were not dissolved and no presence of the target product was detected. In order to dissolve the sodium salts of fatty acids it was necessary to use DMF as a solvent. After completion of the reaction, DMF was evaporated from the system and used in the synthesis with no further purification.

\section{Analysis of surface morphology}

The obtained silane RPTMS was employed to create a coating that would protect wood against water. Hydrolysis and condensation reactions occurred in the prepared sol-gel solutions (Mai and Militz 2004a; Subasri et al. 2013). The former led to the formation of $\mathrm{Si}-\mathrm{OH}$ groups from water. The subsequent two types of condensation reactions between $\mathrm{Si}-\mathrm{OH}$ and $\mathrm{Si}-\mathrm{O}-$ $\mathrm{CH}_{3}$ moieties created a well-developed, cross-linked network consisting of Si-O-Si covalent bonds. Wood$\mathrm{O}-\mathrm{Si}$ covalent bonds were formed as a result of reactions occurring between $-\mathrm{OH}$ groups present in wood and $\mathrm{Si}-\mathrm{OH}$ and $\mathrm{Si}-\mathrm{O}-\mathrm{CH}_{3}$ groups which were present in the solution. In this way, the coating was attached to the surface of the modified element. Moreover, the aliphatic chain bonded to the silicon atom makes the surface of wood more hydrophobic compared to the unmodified sample.

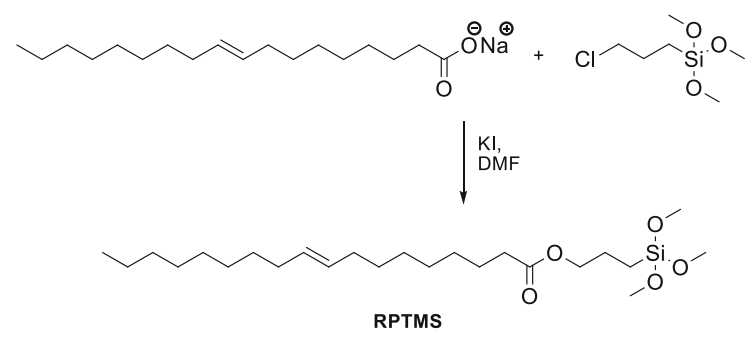

Scheme 1 Synthesis of rapeseed-based silane RPTMS
Figure 1 shows SEM images of the surface of bare wood and samples coated with RPTMS (O1-O3). In the SEM image of bare wood, sharp edges of uncoated wood are visible, while in the case of SEM images of modified samples one can see a layer that coats the surface of wood. Additionally, in the SEM images of samples $\mathbf{O 1}$ and $\mathbf{O 2}$, spherical structures are visible on their surfaces. A likely reason for the presence of aforementioned structures is the retention of solution drops by the wood surface after the samples of wood were removed from solutions followed by the solvent evaporation during which the silane began to condense. The spherical structures are bigger in the case of the sample $\mathbf{O 2}$ due to hydrolysis of tetraethoxysilane in the solution. In the SEM image of sample O3 visible are characteristic cracked structures probably originated from silica. The extension of stirring time of the solution before the process of wood surface silanization could result in the formation of more condensed polysiloxane and silicate structures in the case when TEOS itself underwent condensation already in the solution. Generally, in the case of wood subjected to silanization with solutions $\mathrm{O} 2$ and $\mathrm{O} 3$, both silicate and organosilicon species are present on its surface.

Figure 2 shows the EDS spectra of bare wood and all the coated samples. The spectra of coated samples show an intensive peak assigned to $\mathrm{Si}$ atoms which provides evidence for the formation of organosilicon layer and a layer of silicate structures (in the case of samples $\mathrm{O} 2$ and $\mathrm{O} 3$ ) on the wood surface. Unfortunately, the EDS analysis of silanized wood indicates the presence on its surface of an additional coating that contains silicon atoms, however, their exact form remains unknown. In the FT-IR spectra (Fig. 3), the bands between 1100 and $1300 \mathrm{~cm}^{-1}$ originating from $\mathrm{Si}-\mathrm{O}-\mathrm{Si}$ groups and wood-O-Si groups are present in the case of silane-coated samples. These bands are partially overlapped with a broad band between 950 and $1100 \mathrm{~cm}^{-1}$ attributed to characteristic peaks of cellulose (see FT-IR spectra of bare wood). There are also strong bands in the range of $2800-3000 \mathrm{~cm}^{-1}$ originating from $\mathrm{C}-\mathrm{H}$ groups and in the range $1650-1700 \mathrm{~cm}^{-1}$ ascribed to $\mathrm{C}=\mathrm{O}$ groups.

Table 2 presents the water contact angle values of bare wood and 01-O3 samples. The WCA measurements show that unmodified surface of bare wood is hydrophilic because its WCA is less than $90^{\circ}$. A different behavior has been observed for the samples 


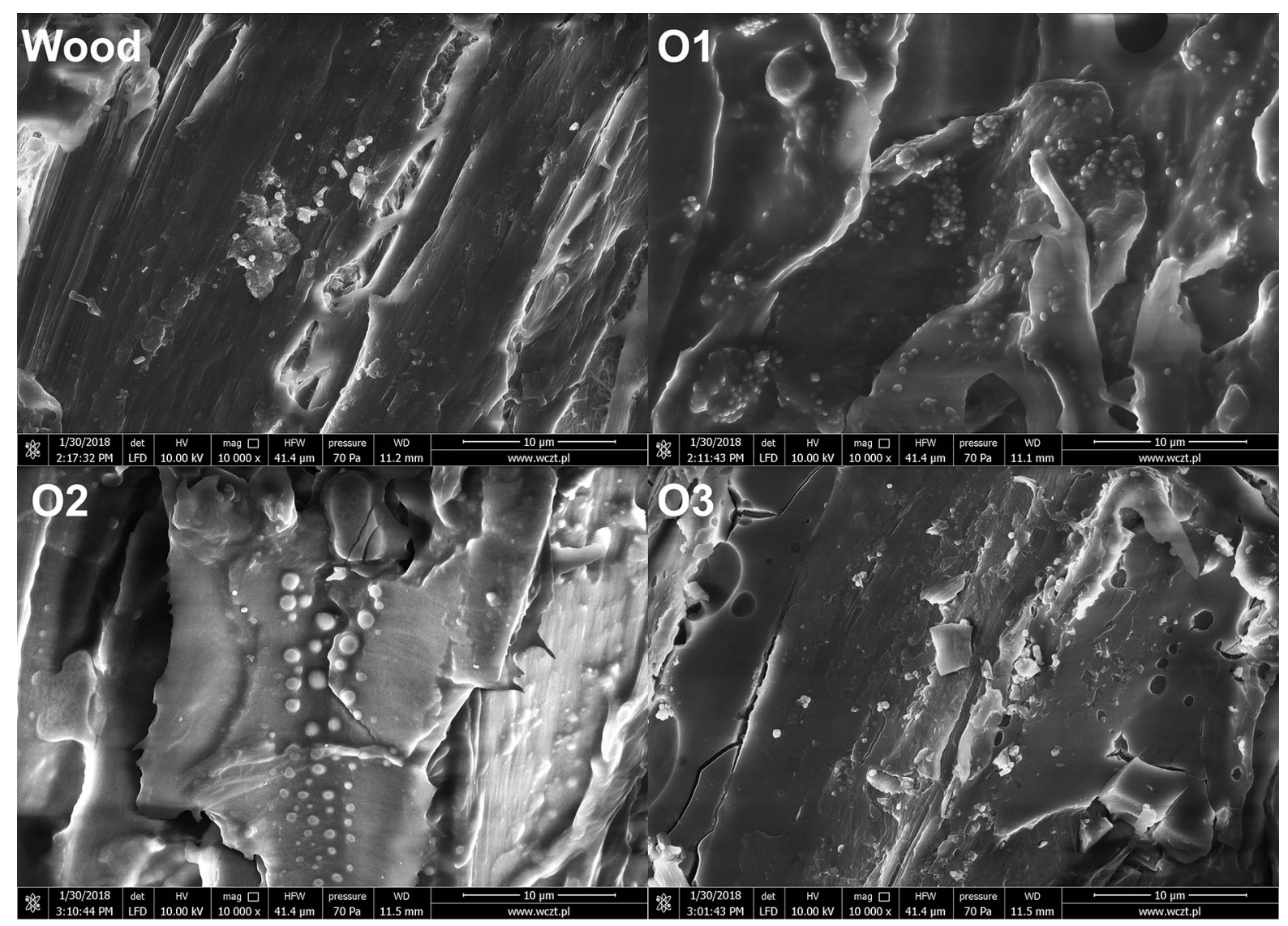

Fig. 1 Scanning electron microscope images of bare pine wood and RPTMS-coated samples O1, 02 and $\mathbf{0 3}$

with modified surfaces, which exhibit hydrophobic properties. Their WCA values are greater than $90^{\circ}$ and equal to $111^{\circ}, 97^{\circ}$ and $92^{\circ}$ for $\mathbf{O 1}, \mathbf{O 2}$ and $\mathbf{O 3}$ samples, respectively. The higher hydrophobicity of sample $\mathbf{O 1}$ probably results from the presence of long hydrocarbon chains on its surface, while in the case of $\mathbf{O 2}$ and O3 samples the hydrocarbon chains can be partially covered by silicate structures due to the presence of TEOS. The hydrocarbon chains can be entangled in the structure of siloxane coating.

All the studied samples were subjected to water absorption measurements and results of the measurements have been collected in Table 3 .

It results from the data presented in Table 3 that bare wood sample has shown high capability of absorbing water because its mass increased by over $50 \%$ after $24 \mathrm{~h}$ contact with water. The wood samples protected with silane RPTMS coatings showed a significant resistance to water absorption.
As was already mentioned, the reaction between hydroxyl groups present on the wood surface with $\mathrm{Si}-$ $\mathrm{OH}$ and $\mathrm{Si}-\mathrm{O}-\mathrm{CH}_{3}$ groups present in solution results in the formation of Wood-O-Si covalent bonds (Mai and Militz 2004a; Subasri et al. 2013). Such bonds are stable (do not undergo hydrolysis), if the coating formed on the wood surface effectively protects them from the access of water. After completing the measurements of water soaking, dried wood samples were subjected to SEM-EDS and FT-IR analyses in order to determine changes that occurred in the formed organosilicon coatings.

Figure 4 shows EDS spectra of coatings before and after water soaking tests. Only in the case of coating $\mathrm{O} 1$, that was based on RPTMS alone, a reduction in the intensity of the peak originating from silicon atoms was observed. The intensity reduction is probably a result of leaching of unreacted silane or a partial hydrolysis of $\mathrm{C}-\mathrm{O}-\mathrm{Si}$ bond. Additionally, for a better identification of silicon-based structures formed on the 

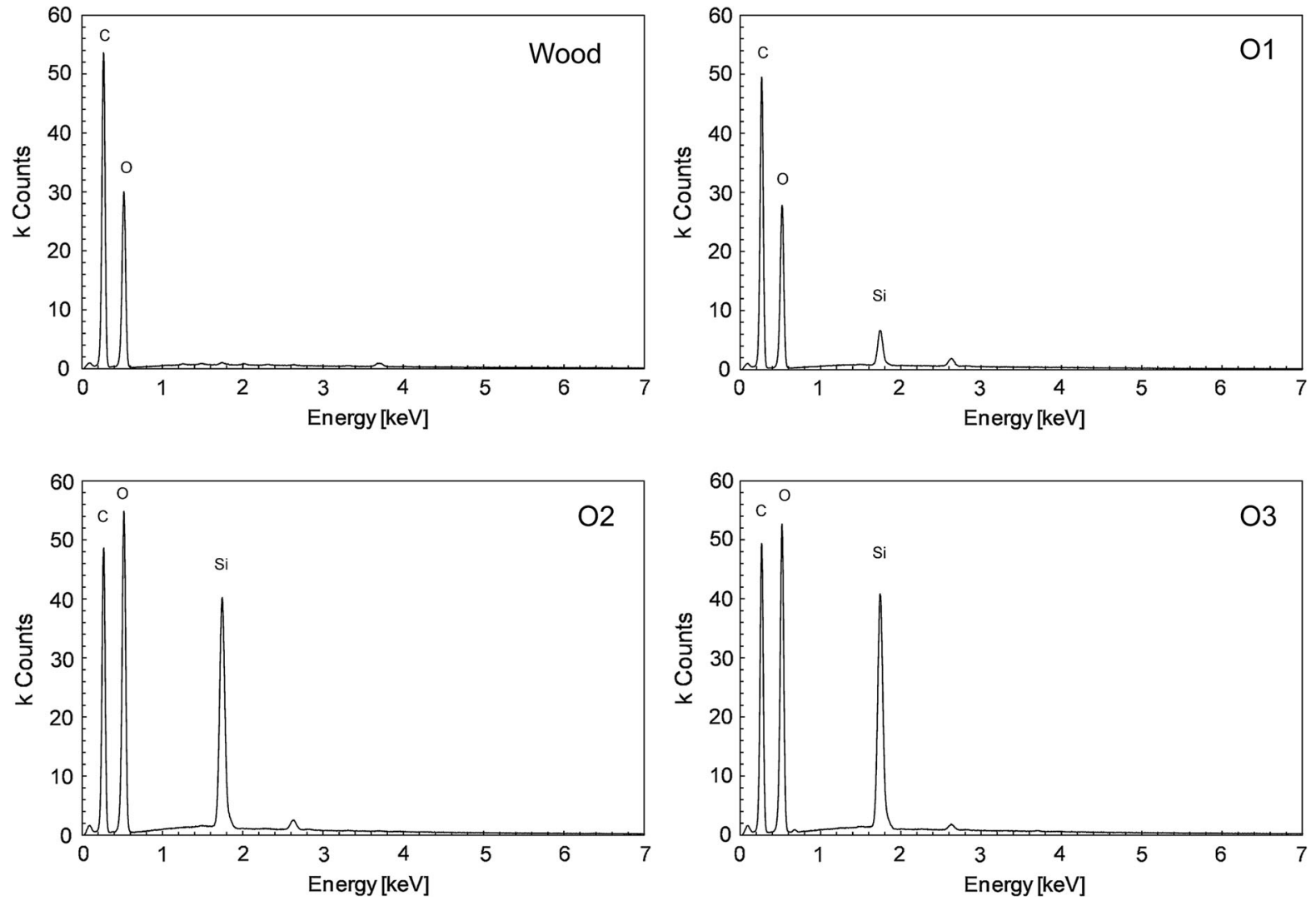

Fig. 2 EDS spectra of bare pine wood and samples 01,02 and $\mathbf{O 3}$

Fig. 3 FT-IR spectra of bare pine wood and samples $\mathbf{0 1 ,} \mathbf{O 2}$ and $\mathbf{O 3}$

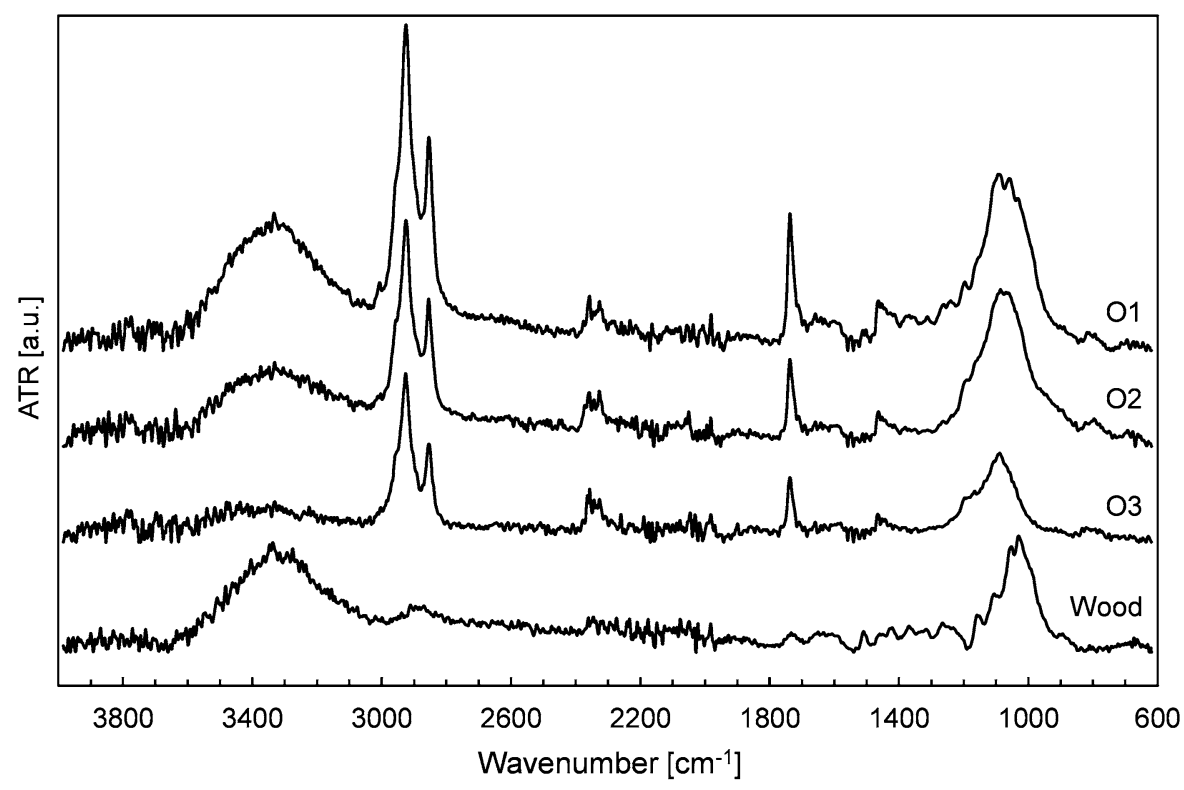

wood surface, EDS mappings were performed of samples subjected to soaking in water. The images presenting carbon and silicon contents on the wood surface are available in Electronic Supplementary 
Table 2 Water contact angle (WCA) values on bare wood and $\mathbf{O 1 - O 3}$ samples

\begin{tabular}{lc}
\hline Sample & WCA/degree \\
\hline Bare wood & 55 \\
O1 & 111 \\
O2 & 97 \\
O3 & 92 \\
\hline
\end{tabular}

Table 3 Comparison of water absorption by bare wood and O1-O3 samples

\begin{tabular}{ll}
\hline Sample & Percentage water absorbed/\% \\
\hline Bare wood & 52 \\
O1 & 13 \\
O2 & 19 \\
O3 & 14 \\
\hline
\end{tabular}

Material. In the images of sample $\mathrm{O} 1$ visible is homogeneous distribution of carbon and silicon on the whole mapped surface. On surfaces of $\mathrm{O} 2$ and $\mathrm{O} 3$ samples, there are areas with a higher saturation with
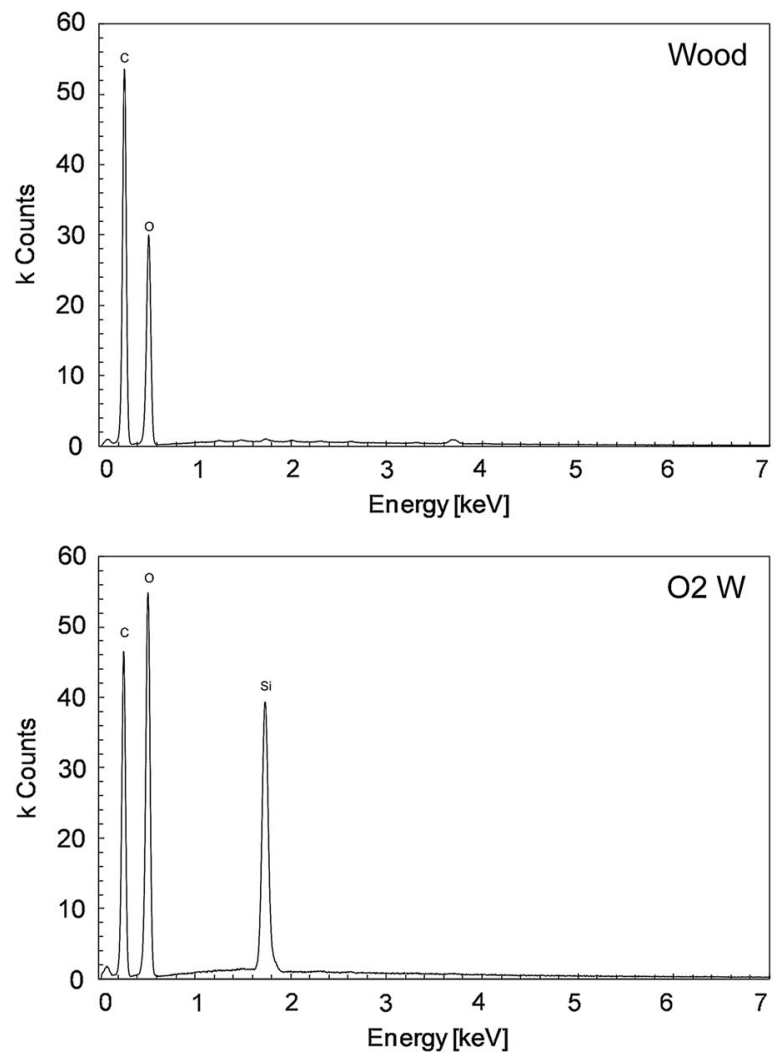

Fig. 4 EDS spectra of O1W, O2W and O3W samples silicon which is a result of the TEOS presence in silanizing solutions. Additionally, cracked structures present on the surface of sample O3, which were earlier ascribed to silicates, are not visible at all in the image showing carbon content in the coating, whereas in the image presenting silicon content in the coating these areas are very light which indicates a large silicon content in them.

The durability of formed coatings and their satisfactory resistance to the hydrolysis in mild conditions has also been confirmed by the results of FT-IR analysis performed for silanized samples after $24 \mathrm{~h}$ soaking in deionized water. It has been established that all characteristic bands that were present in the FT-IR spectra of O1-O3 samples (Fig. 3) were retained in the spectra of water-soaked samples, O1W-O3W, subjected to drying prior to spectra recording (Fig. 5). A minor decrease in the relative intensity of the discussed FT-IR spectra can be a result of leaching of unreacted silanes, partial hydrolysis of $\mathrm{Si}-\mathrm{O}-\mathrm{C}$
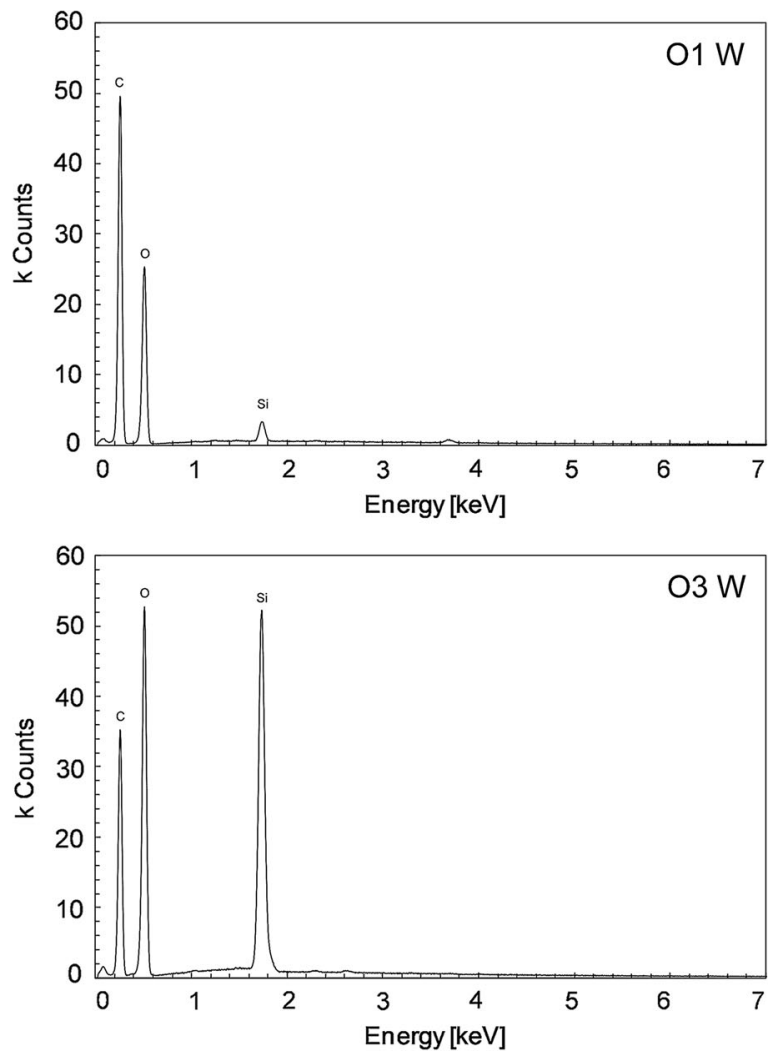
Fig. 5 FT-IR spectra of bare pine wood and silanized wood samples after $24 \mathrm{~h}$ soaking in water (O1W-O3W)

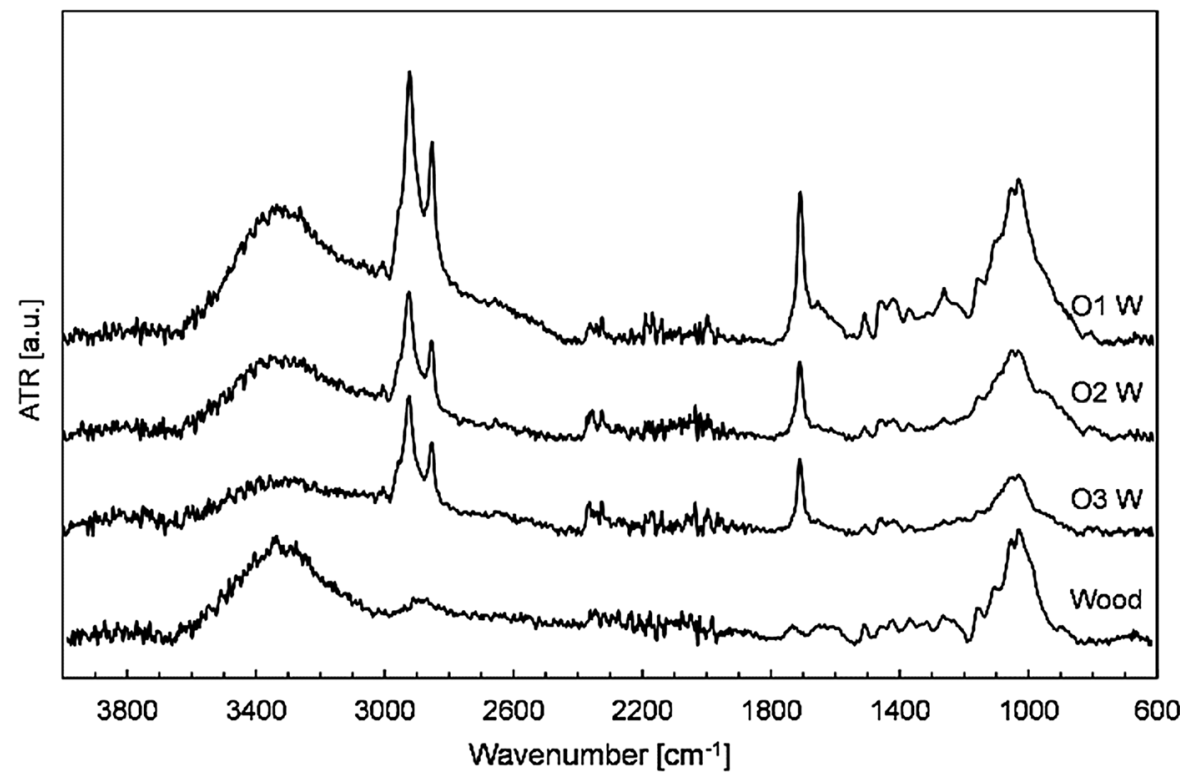

bonds, heterogeneity of wood surface and as a consequence also coatings formed on such a surface.

\section{Conclusions}

A new silylated rapeseed oil derivative has been synthesized and used for the preparation of protective coatings to be applied on the wood surface. Siloxane films have been successfully deposited on the wood surface by immersion in the silane solution. Due to formation of chemical bonds between the wood surface and silane (Wood-O-Si bonds), the coating provides a durable modification of wood. A partial coating degradation was observed only in the case of the coating based on RPTMS alone (sample O1), whereas other studied coatings did not degrade during soaking of samples in water. Synthesis of the silane derivatives of rapeseed oil opens new possibilities of using natural products for obtaining organosilicon derivatives and the application of the latter to the generation of protective coatings strongly bonded to the surface of protected material. Such a silane is also a good alternative to fluorosilanes that are commonly used as hydrophobic agents.

Acknowledgments This work was supported by funds from the National Science Centre (Poland) granted on the basis of decision number DEC-2013/09/D/ST5/03845.
Open Access This article is distributed under the terms of the Creative Commons Attribution 4.0 International License (http:// creativecommons.org/licenses/by/4.0/), which permits unrestricted use, distribution, and reproduction in any medium, provided you give appropriate credit to the original author(s) and the source, provide a link to the Creative Commons license, and indicate if changes were made.

\section{References}

Backer MW, Gohndrone JM, Kleyer DL, Zhou X (2016) Esterfunctional silanes and the preparation and use thereof; and use of iminium compounds as phase transfer catalysts. U.S. Patent 9518072

Biermann U, Friedt W, Lang S, Luehs W, Machmueller G, Metzger JO, Klaas MR, Schaefer HJ, Schneider MP (2000) New synthesis with oils and fats as renewable raw materials for the chemical industry. Angew Chem Int Ed 39:2206-2224

Biermann U, Bornscheuer U, Meier MAR, Metzger JO, Schaefer HJ (2011) Oils and fats as renewable raw materials in chemistry. Angew Chem Int Ed 50:3854-3871

Bocianowski J, Mikołajczyk K, Bartkowiak-Broda I (2012) Determination of fatty acid composition in seed oil of rapeseed (Brassica napus L.) by mutated alleles of the FAD3 desaturase genes. J Appl Genet 53:27-30

Carré P, Pouzet A (2014) Rapeseed market, worldwide and in Europe. OCL 21(1):D102

Goodell B, Nicholas DD, Schultz TP (2003) Wood deterioration and preservation: advances in our changing world. In: ACS symposium \#845. American Chemical Society Publication, Washington, DC

Gunstone FD (2004) The chemistry of oils and fats. CRC Press LLC, Boca Raton 
Gunstone FD, Hamilton RJ (2001) Oleochemical manufacture and applications, 1st edn. Sheffield Academic Press, Sheffield

Mai C, Militz H (2004a) Modification of wood with silicon compounds. Inorganic silicon compounds and sol-gel systems: a review. Wood Sci Technol 37:339-348

Mai C, Militz H (2004b) Modification of wood with silicon compounds. Treatment systems based on organic silicon compounds-a review. Wood Sci Technol 37:453-461

Marney DCO, Russell LJ (2008) Combined fire retardant and wood preservative treatments for outdoor wood application-a review of the literature. Fire Technol 44:1-14

Naumann A, Seefeldt H, Stephan I, Braun U, Noll M (2012) Material resistance of flame retarded wood-polymer composites against fire and fungal decay. Polym Degrad Stab 97:1189-1196

Ronda JC, Lligadas G, Galià M, Cádiz V (2011) Vegetable oils as platform chemicals for polymer synthesis. Eur J Lipid Sci Technol 113:46-58
Shahidi F (2005) Bailey's industrial oil and fat products, 6th edn. Wiley, New York

Spitz L (2004) Sodeopec: soaps, detergents, oleochemicals and personal care products. AOCS Press, Champaign

Stuart B (2004) Infrared spectroscopy: fundamentals and applications. Wiley, New York

Subasri R, Reethika G, Rama K, Raju CS (2013) Multifunctional sol-gel coatings for protection of wood. Wood Mater Sci Eng 8(4):226-233

Tshabalala MA, Gangstad JE (2003) Accelerated weathering of wood surfaces coated with multifunctional alkoxysilanes by sol-gel deposition. J Coat Technol 75:37-43

Tshabalala MA, Sung LP (2007) Wood surface modification by in situ sol-gel deposition of hybrid inorganic-organic thin films. J Coat Technol Res 4:483-490

Xia Y, Larock RC (2010) Vegetable oil-based polymeric materials: synthesis, properties, and applications. Green Chem 12:1893-1909 